\title{
Ethics Evolve
}

\author{
PETER LACHMANN \\ Department of Veterinary Medicine, Madingley Road, Cambridge CB3 0ES, UK. \\ E-mail: pj11000@cam.ac.uk
}

\begin{abstract}
It is argued that patterns of behaviour that distinguish human 'moral communities' have evolved culturally and been subject to natural selection. For this to work, these behaviour patterns must be maintained stably over substantial numbers of people and periods of time. Religious prescription - which is essentially equivalent to ethics - has provided this stability. ${ }^{1-3}$ It follows that ethics must also have evolved and been subject to natural selection.
\end{abstract}

By re-queening a honey bee colony it can readily be shown that patterns of behaviour that vary from one colony to another are entirely genetically determined and that the newly emerging workers learn nothing from those they grow up among. Analogous experiments in humans - by moving babies from one population to another - give the opposite result. In humans, behavioural differences are learned and not inherited - and therefore so are ethics.

One consequence of this conclusion is that there can be no 'natural law'; another is the realisation that Thomas Huxley was wrong in believing that ethics exist to counteract 'the cosmic struggle' when in fact they form its building blocks; and a third is that religions have to be intolerant of other prescriptions if they are to fulfil this function.

In the modern world, much practical ethical prescription has been ceded to secular law and it will be argued that only where this has occurred is it possible to have any form of multiculturalism. Even then, resistance to the secular consensus, particularly among those with strongly held beliefs, persists.

\section{Natural Law and the Evolution of Ethics}

One of the consequences of accepting religion as an evolutionary adaptation, and of religious prescription as the building block of cultural evolution, is that it becomes necessary to accept that there is no universal or eternal code of ethics. A second consequence is that we must believe that ethics itself evolves culturally and has done so observably over historical time.

This carries with it the rejection of natural law, a very long-standing philosophical thesis that is derived originally from the Stoics via Aristotle and St Thomas Aquinas into 
current religious philosophy, particularly among Roman Catholics. Although a philosophical theory of this age and complexity is not easily or briefly epitomised, this definition by the philosopher Jonathan Dolhenty ${ }^{5}$ sums it up fairly:

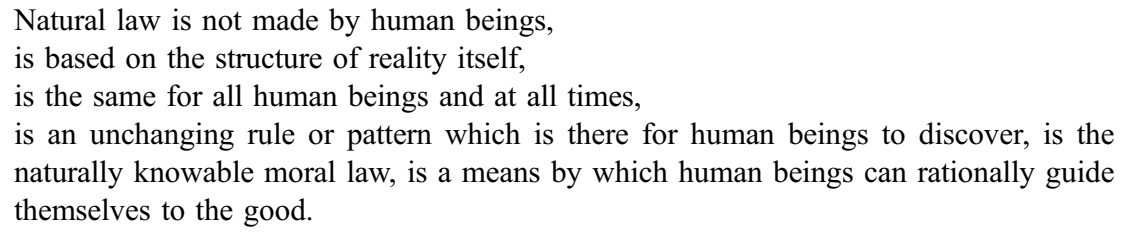

This whole concept of an unchanging ethical structure, which is the same for all human beings and at all times is incompatible with religious and ethical prescription acting as the building blocks of cultural evolution. Importantly it is also, even on cursory inspection, very unlikely to be true.

It is true that there are certainly a number of moral precepts or ethical prescriptions that seem not to vary among different religious prescriptions and seem to have been maintained by virtually all the cultures of which we know. These include altruism, respect for human life and dignity and truthfulness. However, cultures have held widely different ethical views on a number of other issues, of which human sacrifice, cannibalism, slavery and suicide are just four examples.

A belief in natural law therefore would imply that many of our ancestor civilisations, which many today hold in high regard - such as the ancient Greeks, who were quite comfortable with slavery; or the high civilisations of the Americas who had an inordinate capacity for human sacrifice and believed this to be a requirement for the continuation of life - were grossly morally defective. The behaviour of the Ancient Greeks and Mesoamericans was indeed horrifying by the standards of today. But the point is that these people (and possibly even their 'victims') saw little wrong in what they were doing as they were acting only within the evolved cultural and ethical norms of their society.

Can one now see on looking back any justification for why these practices, which contemporary ethical culture has largely rejected, might have had a selective advantage in the past? Slavery is an interesting example. Ancient warfare seems, to some extent, to have been of two separate kinds. In one, the victorious side drove out all the population they had conquered, or killed them all and took their land.

Alternatively, they killed all or most of the men but took the women as slaves. This second type of warfare can still be recognised in the story of the rape of the Sabine women in the early history of Rome.

Taking captive women as slaves may be the oldest form of slavery and may well have carried a selective advantage in the enlargement of the gene pool that would result from interbreeding with a separate population. In the rather small population pools that would have existed in Neolithic times and before, this may have led to selective success, particularly in resisting contagious disease by bringing in a larger variety of variants in the genes involved in immunity.

Cannibalism has been found in modern times only in remote populations and there may be a good reason why it died out. This reason has nothing to do with the morality of eating the dead but with the transmission of spongiform encephalopathies. Here we have 
the real example of the Fore tribe in New Guinea, who practised a form of ritual cannibalism out of respect for the dead rather than any enmity towards their victims.

Unfortunately this practise gave rise to an epidemic of Kuru, a spongiform encephalopathy that very nearly wiped out the tribe in the first half of the twentieth century. Only the prohibition of cannibalism by the Australians who then governed New Guinea allowed this population to survive.

Human sacrifice also has an ancient history, as can be seen in the story of Abraham prepared to sacrifice his son Isaac, a story described in the Old Testament. It was practised to an extraordinary extent by American cultures from the Incas and their predecessors to the Aztecs.

It is difficult to see now what advantage this might have brought to the people that practised it. It is conceivable that as a method of population control it avoided depletion of resources in marginal communities. This might be argued along the lines of forms of ritual suicide described among some Pacific islanders by the American scientist and author Jared Diamond in his book Collapse: How Societies Choose to Fail or Succeed. ${ }^{4}$

This is unlikely to have been the case in the Americas where resources seem to have been plentiful. Attitudes to suicide are still variable among contemporary cultures and the right to die is regarded by many as a corollary to the right to life. There is no obvious reason why the moral rejection of suicide should be unadaptive, although this may well be part of the general moral ethic of an endangered species whose primary concern is to increase its numbers.

Some ethical evolution has been observed in recent times. It has been suggested that it was the Reformation that brought with it the ethical demand that traders should ask only the lowest price that they were willing to accept rather than to rely on bargaining with their customers to produce a sale. If so, this came from views on salvation and was not directly aimed at promoting capitalism. Certainly the Enlightenment brought with it huge advances in moral philosophy and the justification of the modern moral prescription in terms of reason. Immanuel Kant's dictum ${ }^{6}$ that 'humanity is an end in itself' encapsulates this moral philosophy quite clearly.

However, it is important to realise that just as genetic evolution has no goal and that evolved innovations are not always successful and may subsequently die out, the same is also true of cultural evolution. The long-standing ethical paradigm of most religious prescriptions enshrines the primary priority of an endangered species - to increase numbers. It is presumably this imperative that lay at the core of the success of the prohibitions of forms of sexual activity that do not give rise to children; of the refusal to allow abortions or contraception and of the imposition as a primary duty on women to bring up children. All these measures, if adhered to, will tend to increase numbers.

It is clear enough that human beings are no longer an endangered species. The reverse is now the case, and the uncontrolled growth in the human population brought about by advances in producing food, in public health and control of infectious disease, has given rise to the opposite situation, where the human population is now recognised as endangering the physical conditions on the planet that are conducive to life - including human life.

It is, therefore, to some extent obvious that a change in all these ethical parameters is urgently needed, but it has proved extremely difficult to bring these about. Some have 
indeed occurred - the emancipation of women is a clear example of an idea that is by no means new, but is now no longer unadaptive, and therefore those populations that allow women to control their own fertility are unlikely to die out. To some extent the same is true of the liberalisation of the attitude to homosexual relationships that do not give rise to children. However, the general acceptance of contraception and the right to abortion are still contested, particularly by the Roman Catholic Church, on the grounds that this is contrary to 'natural law'.

Much more disturbingly, the events of the twentieth century showed that there are ways of trying to deal with these problems that are much worse than the disease. The outstanding example of this was National Socialism in Germany, which was a secular religion based on a doctrine of racial superiority and the belief that the solution to many of the problems produced by modern advances was to destroy 'inferior races'.

This was believed, by the Nazis themselves, to be a 'Darwinian' solution but amounted to a gross misunderstanding of social Darwinism. Nevertheless, the behavioural prescription of the Nazis, which was enforced largely by physical coercion, did achieve for a few years, in Germany, quite astonishing acceptance by the population.

Of course this prescription turned out to be highly disadvantageous to the Nazis, as can be seen in the result of the Second World War. Nevertheless, the existence of Nazism is deeply disturbing, particularly to all those who believe that ethical progress is inevitable, i.e. those who have a Lamarckian view of cultural evolution rather than the harsher Darwinian view.

World Communism enshrined a similar misunderstanding of Darwin, although the Marxian ideal was less vicious than that of the National Socialists. That said, in the hands of Stalin or Pol Pot or Mao, the vicious and wholesale eradication of certain classes was held to be a prerequisite for building the society they felt was ethically desirable.

One must therefore conclude that ethics has evolved and will continue to evolve by natural selection and this does carry with it the conclusion that there is probably neither prospect nor advantage in trying to secure a single universal ethic on issues that are in any way controversial, i.e. the universal ethic will be of a very general kind, enshrining those dictates that have been selected over very many cultures over very long periods of time, such as general rights to life, liberty and property.

All others need to compete so they can be tested by selection to see what is advantageous to the community in which we now live. However, as the human population now fills the planet, the time scales to allow such competition to occur will be shorter than they have been in the past and there may have to be more general agreement on such things as controlling climate change or the exhaustion of essential resources, which cannot be done just for one population when other larger populations do the reverse. To some extent, therefore, we are in a new environment, which will affect the ways by which cultural evolution can produce its results.

\section{References}

1. P.J. Lachmann (1983) Why religions? An evolutionary view of the behaviour of bees and men. Cambridge Review, 104, pp. 22-26.

2. P.J. Lachmann (2010) Religion - An evolutionary adaptation. FASEB Journal, 24, pp. 1301-1307. 
3. P.J. Lachmann (2010) Genetic and cultural evolution: from fossils to proteins; and from behaviour to ethics. European Review, 18, pp. 297-309.

4. J. Diamond (2005) Collapse: How Societies Choose to Fail or Succeed.

5. J. Dolhenty. An overview of natural law theory. http://www.radicalacademy.com/ philnaturallaw.htm

6. I. Kant (2005) Groundwork of the Metaphysics of Morals (Translated by J. Bennett) Chapter 2, p. 29. http://www.earlymoderntexts.com/pdf/kantgrou.pdf

\begin{abstract}
About the Author
Peter Lachmann is emeritus professor of immunology in the University of Cambridge and a fellow of Christ's College - where Darwin was a student and remains a presence. He has been president of the UK Academy of Medical Sciences and Biological Secretary of the Royal Society and was one of the original members of the UNESCO International Bioethics Committee. From his research into the genetics and evolution of the complement system he developed a broader interest in molecular evolution. Keeping bees as a hobby and comparing bees with humans sparked a further interest in cultural and behavioural evolution.
\end{abstract}

